\title{
Effect of Carbonaceous Reducers on Carbon Emission during Silicon Production in SAF of 8.5 MVA and 12.5 MVA
}

\section{Kaizhi Jiang}

Kunming University of Science and Technology - Lianhua Campus: Kunming University of Science and Technology

Zhengjie Chen ( $\nabla$ czjkmust@126.com )

Kunming University of Science and Technology

\section{Wenhui Ma}

Kunming University of Science and Technology - Lianhua Campus: Kunming University of Science and Technology

\section{Shijie Cao}

Kunming University of Science and Technology - Lianhua Campus: Kunming University of Science and Technology

\section{Hongmei Zhang}

Kunming University of Science and Technology - Lianhua Campus: Kunming University of Science and Technology

\section{Yaqian Zhu}

Kunming University of Science and Technology - Lianhua Campus: Kunming University of Science and Technology

\section{Research Article}

Keywords: Carbonaceous Reducers, Carbon Emission, Silicon Production, Different type of submerged arc furnaces

Posted Date: August 26th, 2021

DOl: https://doi.org/10.21203/rs.3.rs-813450/v1

License: (c) (i) This work is licensed under a Creative Commons Attribution 4.0 International License. Read Full License 


\title{
Effect of Carbonaceous Reducers on Carbon Emission during Silicon
}

\section{Production in SAF of 8.5 MVA and 12.5 MVA}

\author{
Kaizhi Jiang ${ }^{1,2}$, Zhengjie Chen ${ }^{1,2,3^{*}}$, Wenhui $\mathrm{Ma}^{1,2,3^{*}}$, Shijie $\mathrm{Cao}^{1,2,3}$, Hongmei \\ Zhang $^{1,2,3}$, Yaqian Zhu ${ }^{1,2,3}$
}

${ }^{1}$ Faculty of Metallurgical and Energy Engineering, Kunming University of Science and Technology, Kunming 650093, China;

2 State Key Laboratory of Complex Nonferrous Metal Resources Cleaning Utilization in Yunnan Province, Kunming University of Science and Technology, Kunming 650093, China;

3 The National Engineering Laboratory for Vacuum Metallurgy, Kunming University of Science and Technology, Kunming 650093, China;

*Corresponding author:

E-mail address: czjkmust@126.com (Z. Chen)

\section{Abstract}

The silicon manufacturing process produces a large amount of carbon emissions, which is of deep concern to the Chinese government. Previous research has calculated the amount of carbon emissions incurred in silicon production, while research on the factors that affect carbon emissions during the silicon production process has been scarce. The effect of the carbonaceous reducers' consumption on the carbon emission during silicon production was investigated using statistical analysis of the actual production data in order to lower the carbon emissions of silicon production. The effect of different type furnaces (8.5MVA and 12.5MVA) on the carbon emission were also investigated in the study. Based on the results, the soft coal has the greatest impact on carbon emissions when using the 8.5MVA submerged arc furnace. When using the 12.5MVA furnace, petroleum coke has the greatest impact on carbon emission. The use of the 12.5MVA furnace reduces the carbon dioxide emissions of the production of one ton of silicon by approximately $74 \mathrm{~kg}$ compared to the 8.5MVA 
furnace. To obtained reduced carbon emissions in silicon production, we suggest that the silicon manufacturers should (1) use the 12.5MVA submerged arc furnace as much as possible; (2) and optimize the ratio of carbonaceous reducing agents in raw materials for the different furnace types.

\section{Kay words:}

Carbonaceous Reducers, Carbon Emission, Silicon Production, Different type of submerged arc furnaces

\section{Introduction}

In the last several decades, due to increasing concern about global warming, energy conservation and carbon emission reduction have attracted intense attention worldwide. China is currently the largest carbon dioxide emitter in the world [1-4]. However, over the last decade, China has made great efforts to slow down the growth of its carbon emissions. In November 2009, China announced its first greenhouse gas emission reduction target. In the 2015 Paris agreement, China committed to reach peak $\mathrm{CO}_{2}$ emission by 2030 and decrease its carbon intensity by $60-65 \%$ by 2030 relative to the 2005 [2]. On December 18th, 2017, the National Development and Reform Commission announced the "National Carbon Emissions Trading Market Construction Plan (Power Generation Industry)", setting the threshold for China's power generation industry to be included in the carbon market [3]. This plan provides guidance for the industrial silicon sector.

Solar energy is a green renewable energy that is usually obtained by conversion of light into electricity by solar photovoltaic cell materials made from crystalline silicon [5]. Current photovoltaic power generation relies largely on polycrystalline. Polycrystalline silicon can be used to manufacture different types of optoelectronic and photonic circuit [6,7]. It can realize different types of optoelectronic and photonic circuits by integrating on the same silicon chip [8]. Therefore, it is highly necessary to study the factors that affect the carbon emissions in the production of industrial silicon used as the raw material for polycrystalline silicon. 
The smelting process of industrial silicon is an extremely energy-intensive industrial process that mainly consumes carbonaceous reducing agents such as petroleum coke, soft coal and wood block that are used to produce silicon via carbon thermal reduction in a submerged arc furnace $[9,10]$. These raw materials as well as the silica used as the silicon source are non-renewable resources and their use gives rise to considerable fossil $\mathrm{CO}_{2}$ emissions. Since the submerged arc furnace consumes the major part of the energy required in the production chain from silica to industrial silicon, it is appropriate to focus on this process. While multiple approaches for reducing the energy requirements and the carbon dioxide emissions of this process have been suggested and investigated, research on the factors that affect carbon emissions during the industrial silicon production process has been scarce.

A variety of methods have been developed for the study of the environmental impact and $\mathrm{CO}_{2}$ emissions of different technologies by researchers around the world. Heijungs et al. [11] discussed three cases using the Human and Ecological Life cycle tool of Systematic Comprehensive Evaluation (HELIAS), but did not proposed the specific factors affecting carbon emissions. Kirschen et al. [12] showed that in the steel industry, the use of natural gas (NG) can help to reduce the total carbon dioxide emissions produced by electric arc furnaces, but this method does not explicitly calculate the amount of carbon dioxide to be reduced. Kang et al. [13] developed a robust IO-LP model, which suggests that China's coal and hydropower technologies are likely to be significantly developed between 2020 and 2050, but there are significant uncertainties in this approach. O'Ryan et al. [14] analyzed data from the Chilean electricity market based on a Computable General Equilibrium (CGE) model, demonstrating that Chile is on track to reduce the country's overall carbon emissions. Takla et al. [9] analyzed the actual and theoretical production processes of industrial silicon, and used exergy and energy analysis to evaluate the resource utilization of industrial silicon production process.

Since the industrial silicon production process is quite similar to the steel production process, we used the method used in the steel industry for the calculation 
of carbon emissions. The studies focusing on the major steel industry methods used to calculate carbon emissions and their mitigation strategies are listed below.

Worrell et al. [15] analyzed the baseline for 1994 energy use and carbon dioxide emissions from US steel manufacture and identified as many as 47 energy-efficient practices and technologies. Helle et al. [16] investigated the potential of the use of biomass in iron industry production. The results shed light on using biomass in steelmaking can effectively reduce carbon dioxide emissions and reduce smelting costs. Mitra1 et al. [17] used genetic algorithms to analyzed solutions that can provide guidance in the search for more sustainable production concepts. Zhang et al. [18] evaluated the potential of waste heat recovery and carbon reduction in a steel plant in northern China. This study demonstrated that for a steelmaking plant with an annual output of 10 million tons, 1.65 million tons of coal equivalent and approximately 5 million tons of carbon dioxide emissions could be saved by adopting low-energy heat recovery technology. By establishing China's 2011 Economic Input-output Life Cycle Assessment (EIO-LCA) model, Li et al. [19] proved that coke and coal are the biggest influencing factors of direct carbon dioxide emissions in the steel industry and put forward corresponding suggestions to reduce carbon emissions. By limiting 61 key constraints, Shen et al. [20] obtained the best solution for the batch-up ratio and energy saving and emission reduction of the steel production system. The maximum energy saving rate per ton of steel could reach $20.63 \mathrm{kgce}$. In view of the high carbon emissions in China's steel industry, other researchers believe that enhancing energy efficiency and the development and application of energy saving/recycling technologies and breakthrough carbon dioxide technologies, as well as the continuous use of renewable energy are important ways to reduce greenhouse gas emissions from the steel industry [21-24].

In previous studies, we determined the correlation coefficients between the different raw material consumption and exergetic efficiency via linear regression on industrial silicon production in the furnace $[25,26]$. We used several artificial neural network (ANN) models to simulate and evaluate the approximate composition 
114 fluctuations of carbon materials and the final power strain and combustion efficiency 115 under different petroleum coke, soft coal, silica and electrode [27-29]. The effects of 116 raw materials, fixed carbon, volatile substances and water contained on the silicon

117 yield and the energy consumption during silicon production were also studied [30-32].

118 Our recent research has turned up evidence of the correlation between the impurity 119 content in silicon products and the consumption of different carbonaceous reducers 120 [33]. These studies provided different method for studying the impact of raw materials 121 on carbon emissions in the industrial silicon production process.

\section{Research method}

\subsection{Silicon production process}

Figure 1 shows the silicon production system that including the feed, electrode, SAF, product, and waste gas and slag treatment systems [9]. The arc formed between the graphite electrode and the production material in the furnace and the resistance of the charge to the current will cause the furnace temperature to exceed $1800^{\circ} \mathrm{C}$. At such high temperature, silica is reduced by a mixture of soft coal, petroleum coke and wood block with certain proportions. To facilitate the calculation of carbon emissions, we adopt simplified equations for the following major reactions:

$$
\begin{aligned}
& \mathrm{SiO}_{2}(\mathrm{~s})+\mathrm{C}(\mathrm{s})=\mathrm{Si}(\mathrm{l})+\mathrm{CO}_{2}(\mathrm{~g}) \\
& \mathrm{SiO}_{2}(\mathrm{~s})+2 \mathrm{C}(\mathrm{s})=\mathrm{Si}(1)+2 \mathrm{CO}(\mathrm{g})
\end{aligned}
$$




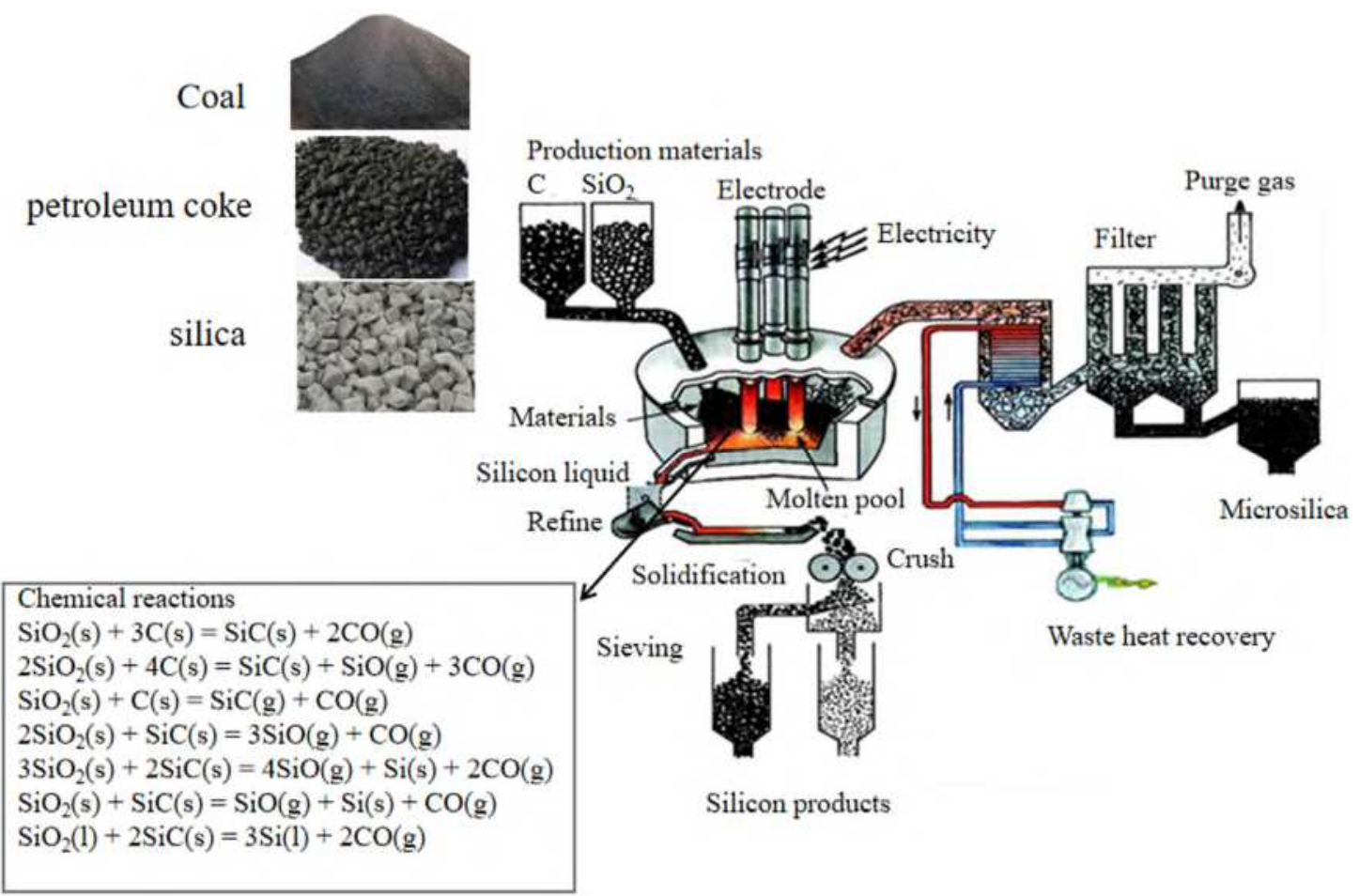

Fig. 1 Industrial silicon production process [9]

\subsection{Raw materials}

The main carbonaceous reducers for the production of industrial silicon include silica, soft coal, petroleum coke, blue carbon, semi-coke, asphalt coke, coke powder, charcoal, wood block, biomass charcoal and so on. Coal, wood block and petroleum coke were used as the carbonaceous reducers, and graphite with a carbon content of $100 \%$ was used as the electrode material. These materials are mainly composed of fixed carbon, volatiles, moisture and ash. Table 1 shows the main components of the carbon-containing feedstock used in the industrial silicon production experiments carried out in this work.

Table 1 Industrial analysis of several carbonaceous reducers (wet basis \%)

\begin{tabular}{ccccc}
\hline Raw materials & Fixed carbon (\%) & Volatiles (\%) & Moisture (\%) & Ash (\%) \\
\hline Petroleum coke & 84.74 & 14.68 & 0.12 & 0.46 \\
Soft coal & 53.37 & 39.55 & 4.70 & 2.38 \\
Wood block & 10 & 32 & 57 & 1 \\
\hline
\end{tabular}




\begin{tabular}{ccccc}
\hline Charcoal & 52 & 10 & 33 & 5 \\
Electrode material & 100 & 0 & 0 & 0 \\
\hline
\end{tabular}

\subsection{Experimental data collection}

In the course of the experiment, we collected a large amount of actual production data through cooperation with an industrial silicon enterprise in Yunnan province and deleted the abnormal data caused by power failure. Analysis of these data reveals the relationship between the raw material consumption and the carbon emission in the process of industrial silicon production in different furnace types. Understanding the relationship between the data is beneficial for reducing production costs and carbon emissions, achieving a more rational and effective use of resources, improving resource utilization and product quality, and protecting the environment.

The 8.5 MVA furnace type was named as 1\# and 2\#, and the 12.5 MVA furnace type was named as $3 \#$ and 4\#. To facilitate comparison and analysis, the data for the consumption of the three kinds of carbonaceous reducers are converted into data for the production of one ton of industrial silicon, and the data unit is ton/ton. We consider that the silicon dioxide content and the electrode material is $100 \%$ fixed and the carbonaceous reducers react completely with silica. All data are analyzed using average values.

\subsection{Carbon emission calculation method}

The carbon emission calculation methods can be divided into three categories: activity level method, mass conservation method and continuous monitoring method. The calculation principle of the activity level method is based on the consumption data and default emission factor. While the calculation method is simple, there is a large uncertainty for the value of the default emission factor. The conservation of mass method is based on the calculation of the carbon difference between the input and output of the enterprise. This method is relatively complex and the calculation results are relatively accurate. However, when a third party uses this method to 
calculate the information asymmetry, the accuracy of the results will be reduced. The continuous monitoring method is a method for the continuous monitoring of related parameters, but it is often difficult for enterprises to monitor all of the emission parameters, and the cost of monitoring is high.

In view of the characteristics of the three methods, currently the most commonly used method is the activity level method. In this work, the study of carbon emissions also used the activity level method to measure the carbon emissions of enterprises.

\subsubsection{Direct emissions}

Direct emissions refer to the $\mathrm{CO}_{2}$ emissions generated by the combustion of fossil fuels, including internal fixed source emissions and mobile source emissions used for production, etc. These emissions can be calculated as follows (the formula is derived from the IPCC Guidelines):

$$
E=\sum A D_{i} \times E F_{i}
$$

where $\mathrm{E}$ is the value of the total carbon emissions caused by the combustion of all fuels in the production of industrial silicon, $i$ is the type of fossil fuel, $A_{i}$ is the total consumption of $\mathrm{i}$, and $\mathrm{EF}_{\mathrm{i}}$ is the $\mathrm{CO}_{2}$ emission coefficient of $\mathrm{i}$. Using the energy recommended carbon emission coefficient formula published in the IPCC guidelines, the carbon emission coefficients of various fuels can be obtained as:

$$
\begin{aligned}
& C=A \times B \times\left(\frac{44}{12}\right) \times 1000 \\
& F=C \times 4186.6 \times 10^{-9} \times 10^{-3} \\
& H=F \times G
\end{aligned}
$$

where $\mathrm{A}$ is the carbon emission coefficient $(\mathrm{kgC} / \mathrm{GJ}), \mathrm{B}$ is the carbon oxidation factor, and all the raw materials for industrial silicon production have the weight of 1 $\mathrm{kg}$ each. $\mathrm{C}$ is the $\mathrm{CO}_{2}$ emission coefficient $\left(\mathrm{kgCO}_{2} / \mathrm{TJ}\right), \mathrm{F}$ is the original coefficient $\left(\mathrm{kgCO}_{2} / \mathrm{kcal}\right), \mathrm{C}$ is the $\mathrm{CO}_{2}$ emission coefficient $\left(\mathrm{kgCO}_{2} / \mathrm{TJ}\right), \mathrm{G}$ is the calorific value $(\mathrm{kcal} / \mathrm{kg})$, and $\mathrm{H}$ is the recommended emission coefficient $\left(\mathrm{kgCO}_{2} / \mathrm{kg}\right)$. It is important to note that the $\mathrm{CO}_{2}$ emission factors used for the calculation are taken from 2006 IPCC Guidelines, because these values are more suitable for the silicon produced in 
China. The calorific values of both wood-solid and charcoal are Chinese calorific values. The calorific value of the wood block is approximately $1.2 \times 10^{7} \mathrm{~J} / \mathrm{kg}$, which is converted into a common unit of 2866800 calories $/ \mathrm{kg}$, or $2866.8 \mathrm{kcal} / \mathrm{kg}$. The calorific value of charcoal is $3.4 \times 10^{7} \mathrm{~J} / \mathrm{kg}$, which means that $3.4 \times 10^{7} \mathrm{~J}$ is released when $1 \mathrm{~kg}$ of charcoal is completely burned and this is converted into a common units to obtain 8122600 calories $/ \mathrm{kg}$, or $8122.6 \mathrm{kcal} / \mathrm{kg}$.

Table 2 Calorific value $\mathrm{G}$ data at standard condition $\left(25^{\circ} \mathrm{C}, 1\right.$ atmosphere $)$

\begin{tabular}{ccccc}
\hline Type of fuel & Soft coal & Petroleum coke & Wood block & Charcoal \\
\hline Calorific value kcal/kg & 6400 & 8200 & 2866.8 & 8122.6 \\
\hline
\end{tabular}

Table 3 Carbon emission coefficient data of each fuel

\begin{tabular}{ccccc}
\hline Type of fuel & Soft coal & Petroleum coke & Wood block & Charcoal \\
\hline Emission coefficient $\mathrm{kgCO}_{2} / \mathrm{kg}$ & 2.53 & 3.35 & 1.35 & 3.81 \\
\hline
\end{tabular}

Using the data in Equation (2.3) and Tables 2 and 3, the carbon emissions from the combustion of fossil energy in the production of industrial silicon can be obtained.

\subsubsection{Emissions from industrial processes}

The carbon emission of industrial production process refers to the $\mathrm{CO}_{2}$ emissions generated by other purchased carbon-containing raw materials such as electrodes in the production process of industrial silicon. The calculation formula is as follows:

$$
E_{\text {electrode }}=P \times E F_{P}
$$

where $\mathrm{E}_{\text {electrode }}$ is the amount of $\mathrm{CO}_{2}$ produced by consuming the electrode $\left(\mathrm{kgCO}_{2} / \mathrm{kg}\right), \mathrm{P}$ is the electrode consumption $(\mathrm{kg}), \mathrm{EFP}_{\mathrm{P}}$ is the $\mathrm{CO}_{2}$ emission factor of the electrode, and its value is $3.6630 \mathrm{tCO}_{2} / \mathrm{t}$. These values are derived from the IISA Guidelines for the Collection of Carbon Dioxide Emission Data.

\subsubsection{Emissions from the use of electricity}

The $\mathrm{CO}_{2}$ emissions are driven by the electricity purchased by industrial silicon manufacturers. The power output consumed by industrial silicon enterprises actually occurs in the power production enterprises and is consumed by industrial silicon 
enterprises. In accordance with the benefit principle, the carbon dioxide emissions embodied in the output power of industrial silicon enterprises are used to calculate the total emissions. The emissions are calculated as follows:

$$
E_{e}=P \times E F_{e}
$$

where $\mathrm{E}_{e}$ is the indirect $\mathrm{CO}_{2}$ emissions generated by the purchased power $\left(\mathrm{kgCO}_{2}\right), \mathrm{P}$ is the power consumption $(\mathrm{kWh}), \mathrm{EF}_{e}$ is the $\mathrm{CO}_{2}$ emission factor of the power consumption in the emission region, and is equal to $0.7035 \mathrm{kgCO}_{2} / \mathrm{kWh}$. The data is derived from the IISA Guidelines for the Collection of Carbon Dioxide Emission Data.

\subsection{Total Carbon Emissions}

On the basis of the above classification, the carbon emissions of industrial silicon enterprises can be divided into direct emissions and indirect emissions according to their emission sources. The direct emissions mainly refer to the emissions from the burning of fossil fuels in the production process, while the indirect emissions mainly refer to the net carbon dioxide emissions generated by the consumption of electricity. Therefore, the calculation formula of total carbon emission is as follows:

$$
E_{\text {total }}=E+E_{\text {electrode }}+E_{e}
$$

Once the total carbon emission values are obtained, the carbon emissions of the five main raw materials electricity, electrodes, petroleum coke, soft coal and wood bloc can be compared. It was found in Fig. 2 that the purchased power produces the largest contribution to carbon emissions, with the average of $63.45 \%$ for the low-rated capacity furnace and $60.85 \%$ for the high-rated capacity furnace. Low-rated capacity furnace type has the largest proportion of petroleum coke emissions, averaging $16.4 \%$, while high-rated capacity furnace type has the largest proportion of soft coal emissions, averaging $17.35 \%$. 


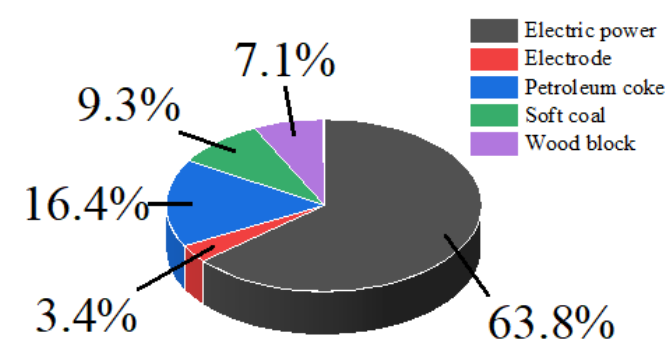

1\# Carbon emission ratio

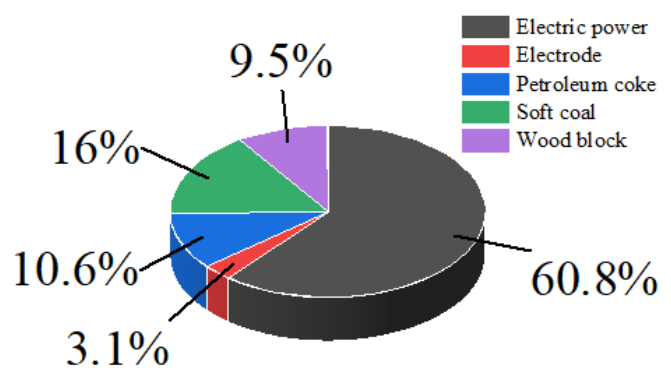

3\# Carbon emission ratio

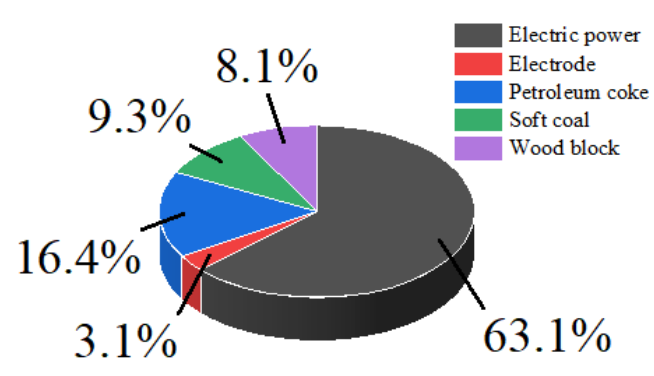

2\# Carbon emission ratio

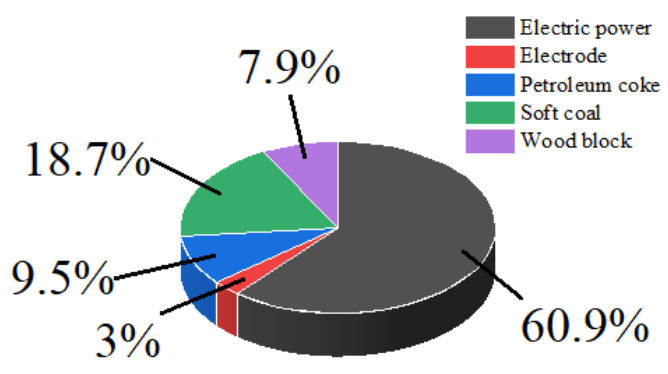

4\# Carbon emission ratio

Fig. 2 The proportion of carbon emission from different furnace

\section{Experimental results and discussion}

\subsection{Effect of carbonaceous reducers on direct carbon emissions}

In order to study the effect of carbon reducing agent consumption on carbon is widely used to evaluate the correlation of variables, and the trend diagram specific relationship is shown as follows [33]:

$$
\mathrm{r}=\frac{\sigma_{x_{i} y_{i}}^{2}}{\sigma_{x_{i}} \cdot \sigma_{y_{i}}}=\frac{\frac{\sum\left(x_{i}-\bar{x}_{i}\right)\left(y_{i}-\bar{y}_{i}\right)}{n}}{\sqrt{\frac{\sum\left(x_{i}-\bar{x}_{i}\right)^{2}}{n} \times \sqrt{\frac{\sum\left(y_{i}-\bar{y}_{i}\right)^{2}}{n}}}}=\frac{\sum\left(x_{i}-\bar{x}_{i}\right)\left(y_{i}-\bar{y}_{i}\right)}{\sqrt{\sum\left(x_{i}-\bar{x}_{i}\right)^{2}} \cdot \sqrt{\left(y_{i}-\bar{y}_{i}\right)^{2}}}
$$


block on the direct carbon emissions. More than 150 groups of experiments were carried out on the three reducing agents containing petroleum coke, soft coal and wood block respectively in $1 \#$ and $2 \#$ furnaces, and then the available data were compared using linear regression analysis. Fig. 3 shows the trend of the three major reducing chemicals and direct carbon emissions, with strong linear correlation observed for all cases. The absolute $\mathrm{r}$ values of 1 \# furnace soft coal, petroleum coke and wood block are $0.94041,0.98248$ and 0.97656 , respectively. The absolute $\mathrm{r}$ values of 2\# soft coal, petroleum coke and wood were 0.92147, 0.96294 and 0.94735, respectively. The absolute values of the straight slope between soft coal, petroleum coke and wood block and carbon emission of 1\# furnace are 8.49575, 6.25631 and 5.8344, respectively, and those of 2\# furnace were 7.30551, 6.41443 and 5.44356, respectively. Based on the analysis of $1 \#$ and 2\# low-rated capacity submerged arc furnaces, it is concluded that soft coal has the greatest impact on the direct carbon emissions generated by the production of single ton of industrial silicon, followed by petroleum coke, and wood block has the least impact.
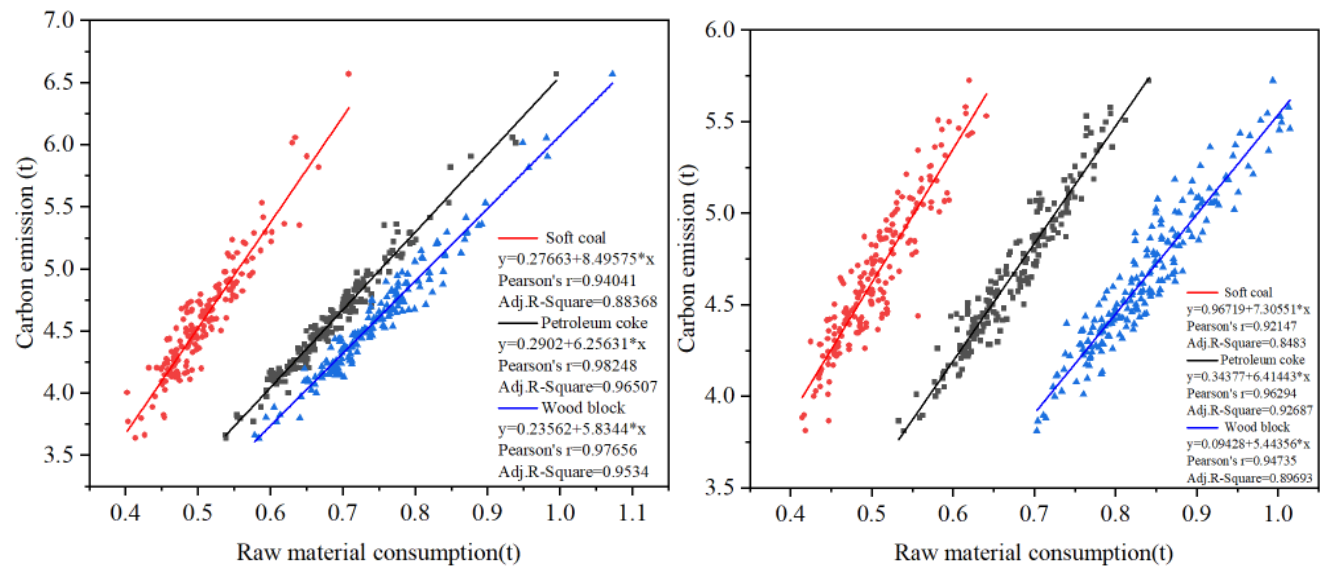

Fig. 3 Relationship between carbonaceous reducers and direct carbon emissions in 1\# and 2\# furnaces

\subsubsection{The 12.5 MVA SAF}

In this section, we mainly analyze the impact of the three reducing agents, namely soft coal, petroleum coke and wood block, on the direct carbon emissions. More than 80 groups of experiments were carried out on the three reducing agents containing soft coal, petroleum coke and wood block in $3 \#$ and $4 \#$ furnaces, 
respectively, and then the available data were compared using linear regression analysis. Fig. 4 shows the variation trend of the three main reducing agent and direct carbon emissions, and strong linear correlation is observed in all cases. The absolute $r$ values of the $3 \#$ furnace soft coal, petroleum coke and wood block are 0.93602, 0.92976 and 0.92912, while the absolute $\mathrm{r}$ values of the $4 \#$ furnace soft coal, petroleum coke and wood block are 0.83585 and 0.880 , respectively. The absolute values of the linear slope between soft coal, petroleum coke and wood block and carbon emission 3\# SAF are 5.76843, 8.3217 and 4.33515, respectively, and those of 4\# SAF are 5.37373 and 11.28009 and 5.09019, respectively. Based on the analysis of 3\# and 4\# high-rated capacity submerged arc furnaces, it is concluded that when using 12.5MVA submerged arc furnace, petroleum coke has the greatest impact on the direct carbon emissions generated by the production of a ton of industrial silicon, followed by soft coal, and wood block has the least impact.
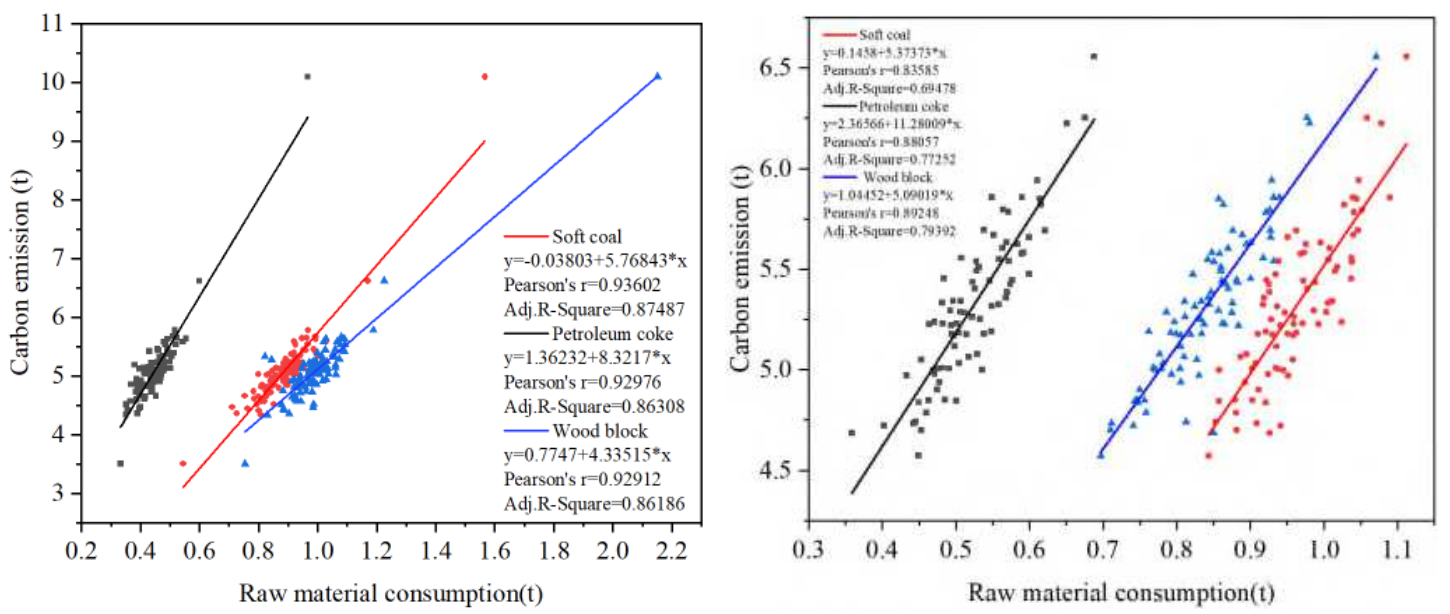

Fig. 4 Relationship between carbonaceous reducers and direct carbon emissions in 3\# and 4\# furnaces

\subsection{Effect of carbonaceous reducers on total carbon emissions}

\subsubsection{The 8.5 MVA SAF}

Similar to 3.1.1, Fig. 5 shows the variation between the three main reducing agents for the total carbon emissions, which also shows a medium linear correlation. The absolute $r$ values of soft coal, petroleum coke and wood block in 3\# furnace are 0.8247, 0.72399 and 0.73295 respectively, and the absolute $\mathrm{r}$ values of soft coal, petroleum coke and wood block in 4\# furnace are 0.87311, 0.87957 and 0.88502, 
respectively. The linear slope between soft coal, petroleum coke and wood block and carbon emission of 1\# submerged arc furnace are 19.29899, 11.79839 and 11.41911, respectively, and those of 2\# submerged arc furnace are 18.18864 and 15.39529 and 13.36241, respectively. Based on 3.1.1, it can be concluded that soft coal has the greatest impact on the total carbon emissions generated by the production of single ton of industrial silicon, followed by petroleum coke, and wood block has the least impact when using 8.5MVA submerged arc furnace.
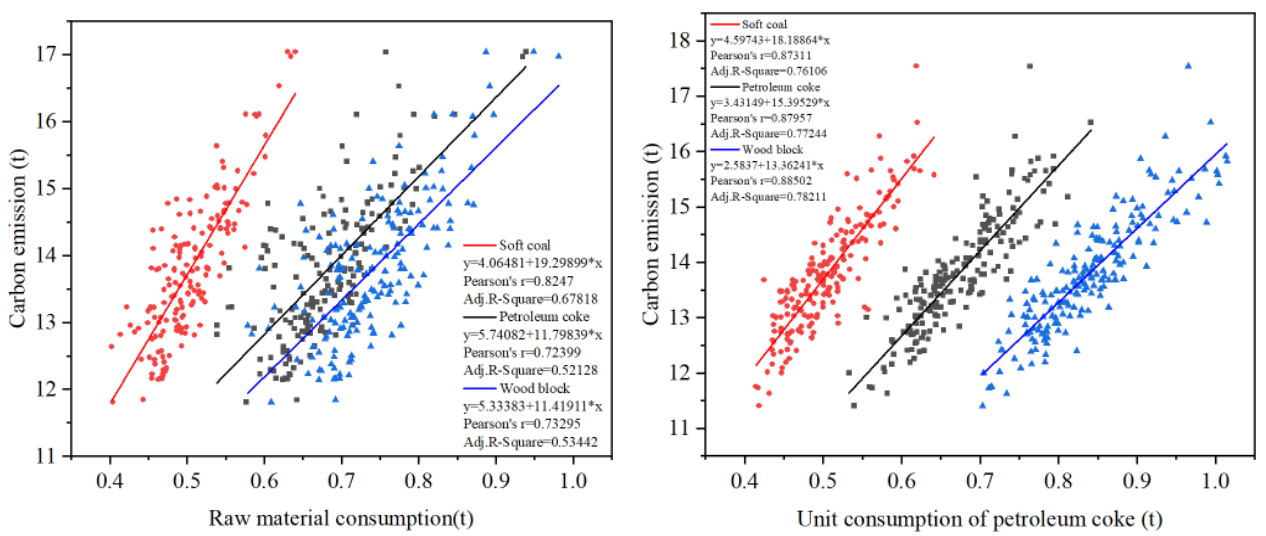

Fig. 5 The relationship between carbonaceous reducers and total carbon emissions in 1\# and 2\# furnaces

\subsubsection{The 12.5 MVA SAF}

Similar to 3.1.2, Fig. 6 shows the variation for the three main reducing chemicals and the total carbon emissions, revealing in some linear correlation. The absolute $r$ values of the $3 \#$ furnace soft coal, petroleum coke and wood block are 0.7265 , 0.81006 and 0.7 , respectively. The absolute values of the linear slope between soft coal, petroleum coke and wood block and carbon emission of the 3\# submerged arc furnace are 8.28397, 13.39245 and 8.04538, respectively, and those of 4\# submerged arc furnace are 11.61836, 13.23908 and 11.49253, respectively. According to 3.1.2, it can be concluded that petroleum coke has the greatest influence on the total carbon emissions generated by the production of a ton of industrial silicon, followed by soft coal, and wood block has the least influence. 

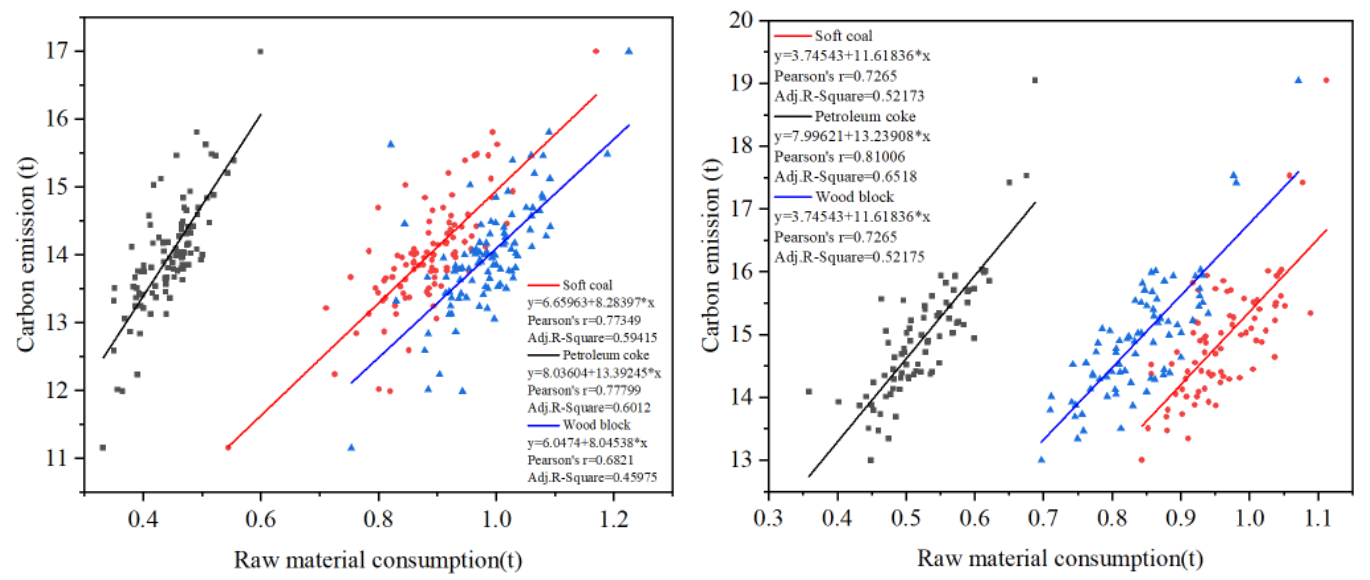

Fig. 6 The relationship between three carbonaceous reducer and total carbon emissions in $3 \#$ and 4 \# furnaces

\subsubsection{Change of the slope of the linear equation between raw material}

\section{consumption and carbon emission under different furnace types}

To more intuitively understand the change of the slope of the linear relationship between different raw materials and carbon emissions under the condition of 8.5MVA and 12.5MVA furnace types, it is drawn as a broken line graph, as shown in Fig. 7. The results show that with the increase in the rated capacity, the slopes of the carbon emissions from coal and wood decreases, while the slope of the carbon emissions from petroleum coke increases. Therefore, we can draw the following conclusion: when using 8.5 MVA furnace, to improve the industrial silicon production and reduce carbon emissions, it is necessary to reduce the usage of soft coal, and increase the use of petroleum coke and block. When using the 12.5MVA furnace, to improve the production of industrial silicon and reduce carbon emissions, it is necessary to reduce the usage of petroleum coke and to increase the usage of soft coal and wood block. 


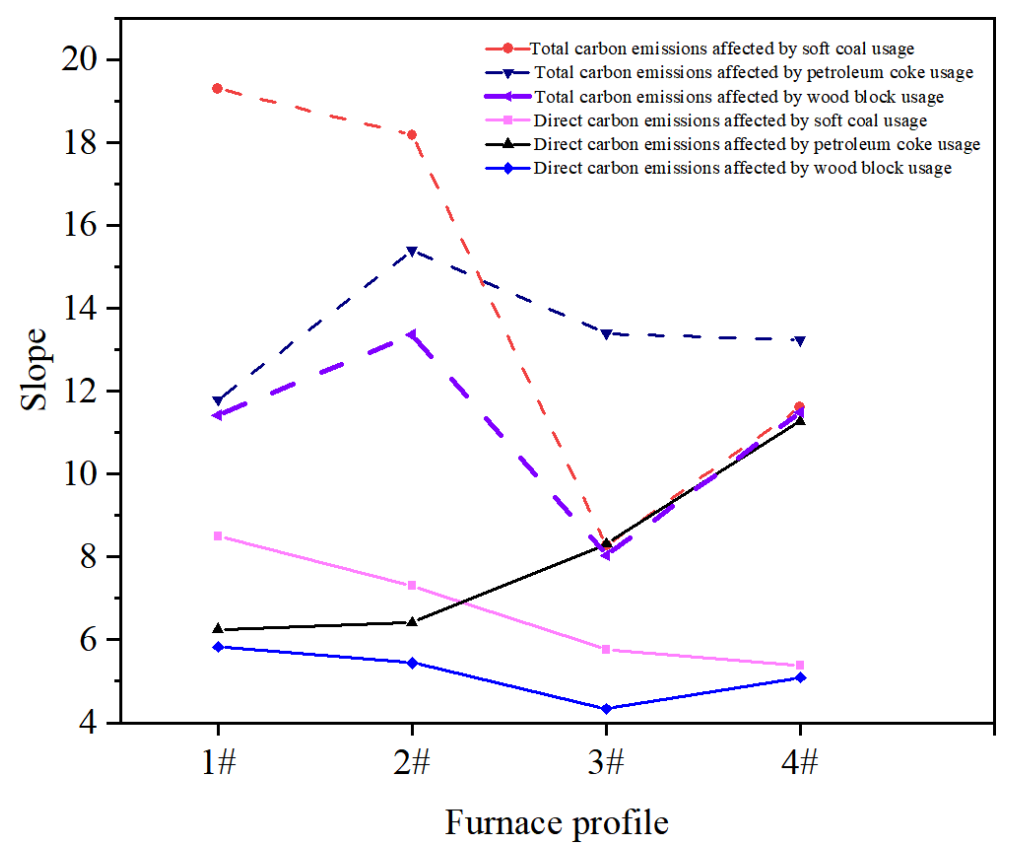

3.2.4 Comparison of average raw material consumption and average

It is clearly observed from Fig. 8, that the power consumption of a ton of 346 industrial silicon produced by different furnace types is essentially maintained at $34712384 \pm 215 \mathrm{kWh} / \mathrm{t}$, and the electrode material consumption is essentially maintained 348 at $0.12 \pm 0.005 \mathrm{t} / \mathrm{t}$. However, the consumption of raw materials varies greatly. The 349 consumption of petroleum coke, soft coal and wood block of the 8.5MVA furnace is 350 essentially maintained at $0.6791 \pm 0.0073 \mathrm{t} / \mathrm{t}, 0.506 \pm 0.0013 \mathrm{t} / \mathrm{t}$ and $0.7915 \pm 0.0460$ $351 \mathrm{t} / \mathrm{t}$. The consumption of petroleum coke, soft coal and wood block of the 12.5MVA 352 furnace is essentially maintained at $0.4839 \pm 0.0397 \mathrm{t} / \mathrm{t}, 0.9234 \pm 0.0391 \mathrm{t} / \mathrm{t}$ and 353 $0.9131 \pm 0.0735 \mathrm{t} / \mathrm{t}$ 


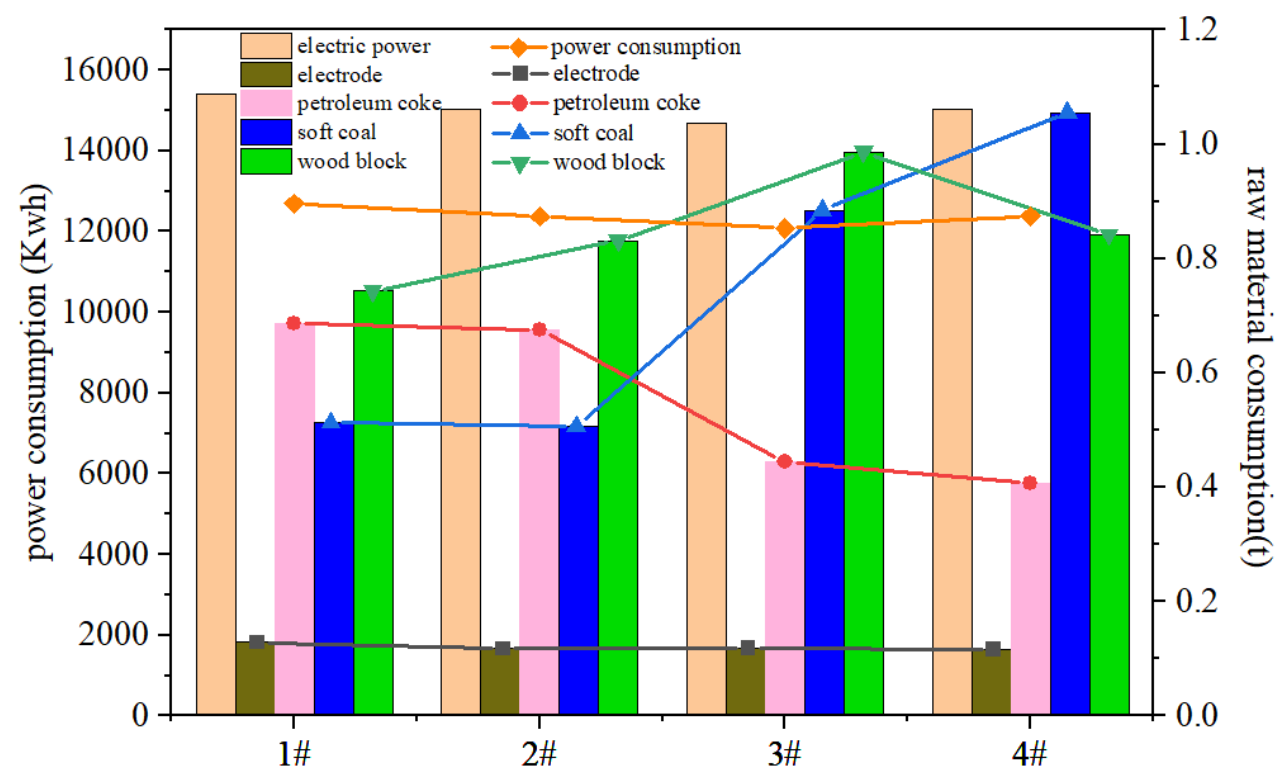

354

355

Average consumption of the two furnace types

Fig.8 Average consumption of electric power, electrode and carbon reducing agent for both furnace types

According to Fig. 9, the direct carbon emission of one ton of industrial silicon produced by the $1 \#$ furnace is $4.5848 \mathrm{t} \pm 0.4350 \mathrm{t} / \mathrm{t}$ and the total carbon emission is $13.9973 \pm 1.6327 \mathrm{t} / \mathrm{t}$. The direct carbon emission of one ton of industrial silicon produced by the $2 \#$ furnace is $4.6476 \pm 0.3683 \mathrm{t} / \mathrm{t}$. The total carbon emission is $14.0241 \pm 0.9400 \mathrm{t} / \mathrm{t}$ and the direct carbon emission of one ton of industrial silicon produced by the $3 \#$ furnace is $5.0520 \pm 0.3356 \mathrm{t} / \mathrm{t}$. The total carbon emission is $13.9339 \pm 0.7835 \mathrm{t} / \mathrm{t}$ and the direct carbon emission of one ton of industrial silicon produced by the $4 \#$ furnace is $5.3182 \pm 0.3802 \mathrm{t} / \mathrm{t}$ and its total carbon emission is $13.9404 \pm 1.1886 \mathrm{t} / \mathrm{t}$. Although the direct carbon emission of the high-rated capacity furnace is higher than that of the low-rated capacity furnace, the total carbon emission of the high-rated capacity furnace is lower than that of the low-rated capacity furnace. We believe that this is because the raw materials of the high-rated capacity furnace incur a too high carbon cost, resulting in large direct carbon emissions. Next, we calculate the excess carbon coefficient and the reasonable batching amount of the high-rated capacity furnace.

Based on the calculation, we conclude that the high-rated capacity furnace reduces the total carbon emission by $0.0736 \mathrm{t} / \mathrm{t}$ on average compared to the low-rated capacity furnace, proving that the use of the 12.5MVA furnace can improve the 
smelting efficiency of industrial silicon and reduce the energy consumption and carbon emission of industrial silicon production.

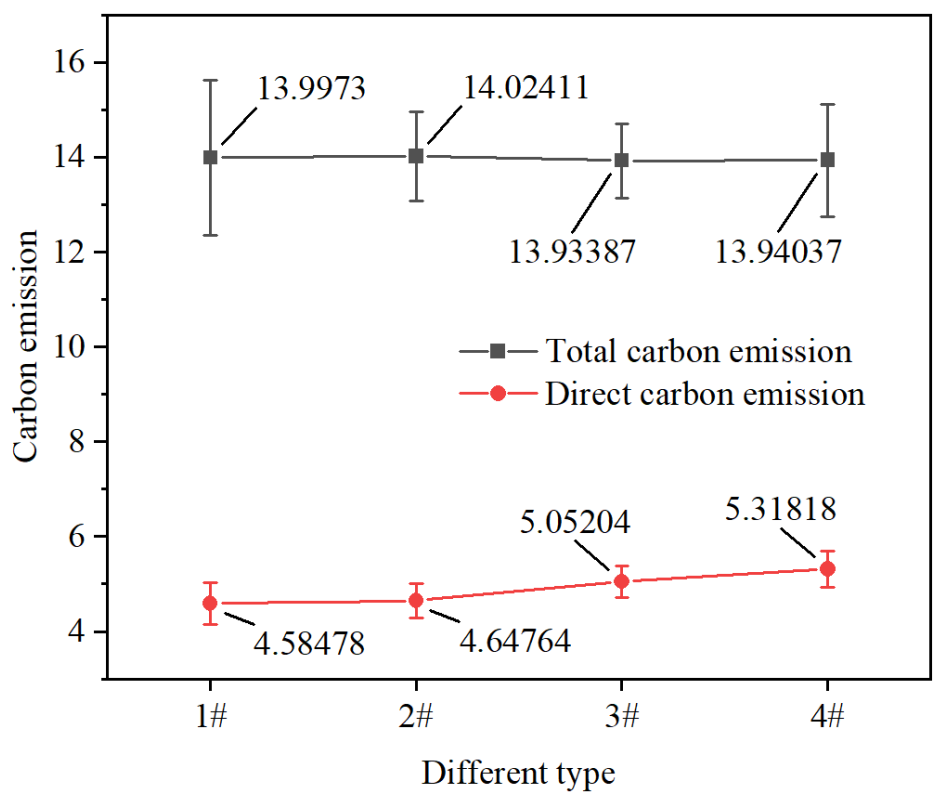

Fig. 9 Comparison of total average carbon emissions and direct carbon emissions of different furnace types

\section{Conclusion}

In this paper, the origins of carbon emission in industrial silicon production are studied. The results show that when using the 8.5MVA furnace, soft coal has the greatest impact on the carbon emissions generated in the production of one ton of industrial silicon, followed by petroleum coke, and wood block has the least influence; when using the 12.5MVA furnace, petroleum coke has the greatest impact on the carbon emissions generated by producing a ton of industrial silicon, followed by soft coal, and wood block has the least influence. The results show that when 8.5MVA furnace is used to produce a ton of industrial silicon, approximately 4.6162 tons of direct carbon emissions and 14.0107 tons of total carbon emissions are generated. When a 12.5MVA furnace is used to produce a ton of industrial silicon, approximately 5.1851 tons of direct carbon emissions and 13.93715 tons of total carbon emissions are generated. Based on the above analysis, we propose that the 12.5MVA submerged arc furnaces are more conducive to energy saving and carbon emission reduction in the process of industrial silicon production. This research is highly significant for improving the industry's market competitiveness, reducing the energy consumption of industrial silicon production, and achieving energy saving and emissions reduction. 
397

398

399

400

401

402

403

404

405

406

407

408

409

410

411

412

413

414

415

416

417

418

419

420

421

422

\section{Acknowledgments}

The authors are grateful for financial support from the National Natural Science Foundation of China (No. 51804147) and the Yunnan Province Department of Education (No. 2018JS018).

\section{References}

1. Huang YM, Xue L, Khan Z (2021) What abates carbon emissions in China: Examining the impact of renewable energy and green investment. Sustainable Development (1):1-12

2. Ding T, Huang YF, He WJ, Zhuang DL (2021) Spatial-temporal heterogeneity and driving factors of carbon emissions in China. Environmental Science and Pollution Research (9):1-14

3. Duan Y, Han ZL, Mu HL, Yang J, Li YH (2019) Research on the Impact of Various Emission Reduction Policies on China's Iron and Steel Industry Production and Economic Level under the Carbon Trading Mechanism. Energies 12:1-26

4. Zhang HN, Zhang XP, Yuan JH (2021) Driving forces of carbon emissions in China: a provincial analysis. Environmental Science and Pollution Research 28:2145521470

5. Green M (2009) The path to $25 \%$ silicon solar cell efficiency: History of silicon cell evolution. Progress in Photovoltaics: Research and Applications 17 (3):183-189 6. Ni ZY, Zhou S, Zhao SY, Peng WB, Yang DR, Pi XD (2019) Silicon nanocrystals: unfading silicon materials for optoelectronics. Materials Science and Engineering: R: Reports 138:85-117

7. Pizzini S, Acciarri M, Binetti S, Cavalcoli D, Cavallini A, Chrastina D, Colombo L, Grilli E, Isella G, Lancin M (2006) Nanocrystalline silicon films as multifunctional material for optoelectronic and photovoltaic applications. Materials Science and Engineering B 134 (2/3):118-124 
8. A DC, A FC, B MC (2000) Components for optoelectronic and photonic integrated circuits - design, modelling, manufacturing and monolithic integration on silicon. Materials Science and Engineering: B 74 (1-3):89-95

9. Takla M, Kamfjord NE, Tveit H, Kjelstrup S (2013) Energy and exergy analysis of the silicon production process. Energy 58:138-146

10. Benioub R, Adnane M, Boucetta A, Chahtou A, Itaka K (2017) Optimization of the Raw Material Input Molar Ratio on the Carbothermal Production of Solar-Grade Silicon. J New Technol Mater 7:90-96

11. Heijungs R, Kleijn R, Voet Evd, Koning Ad, Oers Lv, Elshkaki A, Huele R, Huppes G, Suh S, Wegener Sleeswijk A (2005) Human and Ecological Life Cycle Tools for the Integrated Assessment of Systems (HELIAS). The International Journal of Life Cycle Assessment 11 (S1):19-28

12. Kirschen M, Risonarta V, Pfeifer H (2009) Energy efficiency and the influence of gas burners to the energy related carbon dioxide emissions of electric arc furnaces in steel industry. Energy 34 (9):1065-1072

13. Kang J, Ng TS, Su B (2020) Optimizing electricity mix for $\mathrm{CO}_{2}$ emissions reduction: A robust input-output linear programming model. European Journal of Operational Research 287 (1):280-292

14. O’Ryan R, Nasirov S, Álvarez-Espinosa A (2020) Renewable energy expansion in the Chilean power market: A dynamic general equilibrium modeling approach to determine $\mathrm{CO}_{2}$ emission baselines. Journal of Cleaner Production 247:119645

15. Worrell E, Price L, Martin N (2001) Energy efficiency and carbon dioxide emissions reduction opportunities in the US iron and steel sector. Energy 26 (5):513-536

16. Helle H, Helle M, Saxen H, Pettersson F (2009) Mathematical Optimization of Ironmaking with Biomass as Auxiliary Reductant in the Blast Furnace. Isij International 49 (9):1316-1324

17. Mitra T, Helle M, Pettersson F, Saxén H, Chakraborti N (2011) Multiobjective Optimization of Top Gas Recycling Conditions in the Blast Furnace by Genetic Algorithms. Advanced Manufacturing Processes 26 (3):475-480 
18. Zhang H, Dong L, Li HQ, Chen B, Tang Q, Fujita T (2013) Investigation of the residual heat recovery and carbon emission mitigation potential in a Chinese steelmaking plant: A hybrid material/energy flow analysis case study (2013). Sustainable Energy Technologies \& Assessments 2:67-80

19. Li L, Lei YL, Pan DY (2016) Study of $\mathrm{CO}_{2}$ emissions in China's iron and steel industry based on economic input-output life cycle assessment. Natural Hazards: Journal of the International Society for the Prevention and Mitigation of Natural Hazards 81 (2):957-970

20. Shen X, Chen LG, Xia SJ, Xie ZH, Qin XY (2018) Burdening proportion and new energy-saving technologies analysis and optimization for iron and steel production system. Journal of Cleaner Production 172 (pt.2):2153-2166

21. Xu C, Da-qiang C (2010) A Brief Overview of Low CO_2 Emission Technologies forIron and Steel Making. Journal of Iron and Steel Research(International) 2010,17(03):1-7.

22. He WD, Zhang C (2017) Research on carbon emission evaluation of China's iron and steel industry. In: International Conference on Industrial Economics System \& Industrial Security Engineering, IEEE.

23. Zhang Q, Li Y, Xu J, Jia GY (2018) Carbon element flow analysis and $\mathrm{CO}_{2}$ emission reduction in iron and steel works. Journal of Cleaner Production $172: 709-723$

24. Jin P, Jiang ZY, Bao C, Hao SY, Zhang XX (2015) The energy consumption and carbon emission of the integrated steel mill with oxygen blast furnace. Resources Conservation \& Recycling:561-574

25. Chen ZJ, Ma WH, Wu JJ, Wei KX, Yang X, Lv GQ, Xie KQ, Yu J (2016) Influence of carbothermic reduction on submerged arc furnace energy efficiency during silicon production. Energy 116 (pt.1):687-693

26. Chen ZJ, Ma WH, Wei KX, Li SY, Ding WM (2017) Effect of Raw Materials on the Production Process of the Silicon Furnace. Journal of Cleaner Production $158: 359-366$ 
482

483

484

485

486

487

488

489

490

491

492

493

494

495

496

497

498

499

500

501

502

27. Chen ZJ, Ma WH, Wei KX, Wu JJ, Lv GQ (2017) Artificial Neural Network Modeling for Evaluating the Power Consumption of Silicon Production in Submerged Arc Furnaces. Applied Thermal Engineering 112:226-236

28. Chen ZJ, Ma WH, Wu JJ, Wei KX, Liu ZW (2017) Predicting the Electricity Consumption and the Exergetic Efficiency of a Submerged Arc Furnace with Raw Materials using an Artificial Neural Network. Silicon 10 (57A):1-6

29. Chen ZJ, Zhou SC, Wei KX, Ma WH, Li SY (2020) Evaluating of the exergy efficiency of the silicon production process using artificial neural networks. Phosphorus, Sulfur, and Silicon and the Related Elements 195 (9):756-766

30. Chen ZJ, Ma WH, Wu JJ, Wei KX, Lei Y, Lv GQ (2017) A Study of the Performance of Submerged Arc Furnace Smelting of Industrial Silicon. Silicon 10(3):1121-1127

31. Chen ZJ, Ma WH, Li SY, Wu JJ, Wei KX, Yu ZQ, Ding WM (2018) Influence of carbon material on the production process of different electric arc furnaces. Journal of Cleaner Production 174 (FEB.10):17-25

32. Chen ZJ, Zhou SC, Ma WH, Deng XC, Li SY, Ding WM (2018) The effect of the carbonaceous materials properties on the energy consumption of silicon production in the submerged arc furnace. Journal of Cleaner Production 191:240-247

33. Zhang HM, Chen ZJ, Ma WH, Cao SJ, Jiang KZ, Zhu YQ (2021) The Effect of Silica and Reducing Agent on the Contents of Impurities in Silicon Produced. 


\section{* Ethics approval and consent to participate}

We don't cover ethics approval and consent to participate. 
* Consent for publication

Not applicable. 


\section{* Availability of data and materials}

All data generated or analysed during this study are included in this published article. 


\section{Competing interests}

The authors declare that they have no competing interests. 


\section{* Funding}

The authors are grateful for financial support from the National Natural Science Foundation of China (No. 51804147) and the Yunnan Province Department of Education (No. 2018JS018). 


\section{* Authors' contributions}

Kaizhi Jiang: Conceptualization, Resources, Writing - review \& editing, Visualization, Validation, Supervision. Zhengjie Chen: Formal analysis, Validation, Data curation, Writing-original draft, Writing-review\&editing. Wenhui Ma:Conceptualization, Methodology, Validation, Formal analysis, Investigation, Data curation. Shijie Cao: Conceptualization, Resources, Visualization, Visualization, Supervision. Hongmei Zhang and Yaqian Zhu: Writing - review \& editing. 


\section{* Authors' information (optional)}

Kaizhi Jiang1,2, Zhengjie Chen1,2,3*, Wenhui Ma1,2,3*, Shijie Cao1,2,3, Hongmei Zhang1,2,3, Yaqian Zhu1,2,3

1 Faculty of Metallurgical and Energy Engineering, Kunming University of Science and Technology, Kunming 650093, China;

2 State Key Laboratory of Complex Nonferrous Metal Resources Cleaning Utilization in Yunnan Province, Kunming University of Science and Technology, Kunming 650093, China;

3 The National Engineering Laboratory for Vacuum Metallurgy, Kunming University of Science and Technology, Kunming 650093, China;

*Corresponding author: E-mail address: czjkmust@126.com (Z. Chen) 


\section{* Disclosure of potential conflicts of interest}

We declare that we have no conflict of interest. 
* Research involving Human Participants and/or Animals

Not applicable 


\section{* Informed consent}

Not applicable 